\title{
Effects of Aged Garlic Extract on Cholinergic, Glutamatergic and GABAergic Systems with Regard to Cognitive Impairment in $A \beta$-Induced Rats
}

\author{
Piyaporn Thorajak ${ }^{1,2}$, Wanassanun Pannangrong ${ }^{1,2}$, Jariya Umka Welbat ${ }^{1,2,3}$, \\ Wunnee Chaijaroonkhanarak ${ }^{1}$, Kittisak Sripanidkulchai ${ }^{1,2}$ and Bungorn Sripanidkulchai ${ }^{2, *}$ \\ 1 Department of Anatomy, Faculty of Medicine, Khon Kaen University, Khon Kaen 40002, Thailand; \\ piyaporn.anatomy@gmail.com (P.T.); wankun@kku.ac.th (W.P.); jariya@kku.ac.th (J.U.W.); \\ cwunnee@kku.ac.th (W.C.); skitti@kku.ac.th (K.S.) \\ 2 Center for Research and Development of Herbal Health Products, Khon Kaen University, \\ Khon Kaen 40002, Thailand \\ 3 Neuroscience Research and Development Group, Khon Kaen University, Khon Kaen 40002, Thailand \\ * Correspondence: bungorn@kku.ac.th; Tel.: +66-43-202-378
}

Received: 30 March 2017; Accepted: 28 June 2017; Published: 1 July 2017

\begin{abstract}
Alzheimer's disease (AD) has been linked to the degeneration of central cholinergic and glutamatergic transmission, which correlates with progressive memory loss and the accumulation of amyloid- $\beta(A \beta)$. It has been claimed that aged garlic extract (AGE) has a beneficial effect in preventing neurodegeneration in $\mathrm{AD}$. Therefore, the objective of this study was to investigate the effects of AGE on A $\beta$-induced cognitive dysfunction with a biochemical basis in the cholinergic, glutamatergic, and GABAergic systems in rats. Adult male Wistar rats were orally administered three doses of AGE $(125,250$, and $500 \mathrm{mg} / \mathrm{kg})$ daily for 65 days. At day 56, they were injected with $1 \mu \mathrm{L}$ of aggregated $\mathrm{A} \beta(1-42)$ into each lateral ventricle, bilaterally. After six days of $A \beta$ injection, the rats' working and reference memory was tested using a radial arm maze. The rats were then euthanized to investigate any changes to the cholinergic neurons, vesicular glutamate transporter 1 and 2 proteins (VGLUT1 and VGLUT2), and glutamate decarboxylase (GAD) in the hippocampus. The results showed that AGE significantly improved the working memory and tended to improve the reference memory in cognitively-impaired rats. In addition, AGE significantly ameliorated the loss of cholinergic neurons and increased the VGLUT1 and GAD levels in the hippocampus of rat brains with A $\beta$-induced toxicity. In contrast, the VGLUT2 protein levels did not change in any of the treated groups. We concluded that AGE was able to attenuate the impairment of working memory via the modification of cholinergic neurons, VGLUT1, and GAD in the hippocampus of A $\beta$-induced rats.
\end{abstract}

Keywords: aged garlic extract; Alzheimer's disease; amyloid- $\beta$; cholinergic neurons; glutamate decarboxylase; radial arm maze; vesicular glutamate transporters

\section{Introduction}

Memory formation is a complex process that is associated with various neurotransmitter systems. Three major systems, including the cholinergic, glutamatergic, and GABAergic, are commonly involved and have predominate roles in the process [1-4]. Acetylcholine (ACh), a neurotransmitter of the cholinergic system, released within the hippocampal circuits is important for learning and memory. It is a powerful presynaptic modulator of both glutamatergic and GABAergic synaptic transmission [1]. Ach is synthesised by the Choline acetyltransferase (ChAT) enzyme which is found in high concentrations in cholinergic neurons as visualized by choline acetyltransferase (ChAT) immunohistochemcal staining. In the modulation of network activity, Ach-activated muscarinic 
acetylcholine receptors either directly [3], or through associative interactions with glutamatergic synaptic inputs, promote longer-term synaptic plasticity [5]. Glutamate, a neurotransmitter of the glutamatergic system, acts as an excitatory transmitter in the major pathways of hippocampal formation. The quantal release of glutamate depends on its transport into synaptic vesicles [6]. Two vesicular glutamate transporters, vesicular glutamate transporters 1 (VGLUT1) and vesicular glutamate transporters 2 (VGLUT2), are the predominant isoforms of the excitatory glutamatergic terminals in the brain. Both transporters mediate glutamate uptake into the synaptic vesicles of glutamatergic neurons [7-9]. The GABAergic system provides reciprocal presynaptic inhibition of cholinergic and glutamatergic inputs through the hippocampus formation activation of $G_{A B} A_{B}$ receptors [10]. GABA is synthesized via the catalytic activity of glutamic acid decarboxylase (GAD) enzymes. Two molecular forms of GAD, expressed in the brain, are GAD 65 and GAD 67 [11].

The hippocampus is associated with spatial learning and memory [12], in which the integration of cognitive and the normal function in glutamatergic and cholinergic systems is necessary for spatial learning [13]. Glutamate and GABA are the major excitatory and inhibitory neurotransmitters in the central nervous system. Integration of excitatory and inhibitory signals is a basic function of neuronal communication [14]. Thus, plasticity of synapses related to learning and memory requires adequate levels of excitation and inhibition to be maintained [15]. Thus, the alteration properties of hippocampal neurons and/or dysfunction of three neurotransmitters are involved in cognitive impairments were found in Alzheimer's disease (AD) [3,16-18].

Amyloid- $\beta(A \beta)$ is known as a major cause of cognitive impairment. Several studies used $A \beta$ to investigate the presence of cognitive disability in rat models as observed by behavioural tests [19-21]. A $\beta$ plaques in the cerebral cortex and hippocampus may relate to the intellectual decline in AD [22]. Previous studies had reported that the neurotoxicity of $A \beta$ peptides involved many neuronal events, such as the deficiency of neurotransmitters, the decrease in vesicular transporters, and synaptic transmissions, leading to neuronal cell death [23-26]. There have been several studies on the neuroprotective effects of natural products in AD models. Several compounds from various plants may have properties that benefit the cholinergic, glutamatergic, and/or GABAergic systems. This information may aid in the study of neuroprotective and cognitive improvement leading to preventative and therapeutic strategies against AD.

Aged garlic extract (AGE) is a garlic (Allium sativum L.) product that has been reported to be beneficial in preventing neurodegeneration because of its antioxidant and $A \beta$-lowering properties [26]. Long-term administration of AGE has been reported to prevent atrophic changes in the forebrain and learning deficits in senescence-accelerated mice [27], as well as to improve short-term recognition memory in $A \beta$-induced rats [28]. In addition, adding AGE to a culture medium has been shown to result in a concentration-dependent increase in the survival and axonal branching of cultured rat hippocampal neurons [29]. However, there is a lack of direct evidence regarding the role of AGE on learning and memory associated with the cholinergic, glutamatergic, and GABAergic systems. Therefore, the present study was undertaken to investigate the beneficial effects of AGE on A $\beta$-induced cognitive dysfunction with a biochemical basis in the cholinergic, glutamatergic, and GABAergic systems in rats.

\section{Materials and Methods}

\subsection{Preparation of Aged Garlic Extract}

AGE was provided by the Center for Research and Development of Herbal Health Products (CRD-HHP) at Khon Kaen University in Khon Kaen, Thailand. AGE was prepared by soaking chopped garlic (obtained from Srisaket province in Thailand) in 30\% ethanol at a 1:3 ratio for approximately 15 months under light protection at room temperature. After filtration, ethanol in the filtrate was removed using a rotary evaporator, leaving dried AGE powder with a percent yield of 3.8. HPLC analysis of AGE revealed the bioactive compounds to be $S$-allylcysteine (SAC) and 
allicin at concentrations of $30.96 \mathrm{mg} / \mathrm{g}$ and $32 \mu \mathrm{g} / \mathrm{g}$, respectively (Petty patent No. 3506, Thailand). The AGE was dissolved in distilled water at concentrations of 125,250 , and $500 \mathrm{mg} / \mathrm{kg}$ BW before being administered to the rats.

\subsection{Animals and Treatment Protocol}

Forty adult male Wistar rats (180-220 g) were purchased from the National Laboratory Animal Center at Mahidol University in Nakhon Pathom, Thailand. With free access to water and standard pellet food (CPF, Saraburi, Thailand), the rats were maintained on a $12 \mathrm{~h}$ light/12 $\mathrm{h}$ dark cycle at $23 \pm 2{ }^{\circ} \mathrm{C}$ at the Northeast Laboratory Animal Center at Khon Kaen University (Thailand). All studies were carried out in accordance with the National Institute of Health (NIH) Guide for the Care and Use of Laboratory Animals, and the experimental design was approved by the Khon Kaen University Institutional Animal Ethics Committee (AEKKU 88/2555). After one week of acclimatization, the animals were divided into five groups, with each group consisting of eight rats. The groups were as follows:

Group 1 (Vehicle control) received distilled water as a vehicle.

Group 2 (Vehicle $+A \beta$ ) received distilled water and were injected with $A \beta(1-42)$ into the lateral ventricle.

Group $3(\mathrm{AGE} 125+\mathrm{A} \beta)$ received AGE $(125 \mathrm{mg} / \mathrm{kg}$ BW, per oral) and were injected with A $\beta$ (1-42) into the lateral ventricle.

Group $4(\mathrm{AGE} 250+\mathrm{A} \beta)$ received AGE $(250 \mathrm{mg} / \mathrm{kg}$ BW, per oral) and were injected with A $\beta$ (1-42) into the lateral ventricle.

Group $5(\mathrm{AGE} 500+\mathrm{A} \beta)$ received AGE $(500 \mathrm{mg} / \mathrm{kg}$ BW, per oral) and were injected with A $\beta$ (1-42) into the lateral ventricle.

Vehicle and AGE solution were orally administered once daily for sixty-five consecutive days. At day 56, the rats in groups $2-5$ were bilaterally injected with $1 \mu \mathrm{L}$ of $\mathrm{A} \beta(1-42)$ into each side of both lateral ventricles. At day 62, all rats were tested for working and reference memory performance using a radial arm maze test (RAM) (Figure 1). At day 65, all rats were anesthetized with an overdose of thiopental sodium (Jagsonpal pharmaceutical Ltd., New Delhi, India) via injection and were transcardially perfused with $0.9 \%$ normal saline solution.

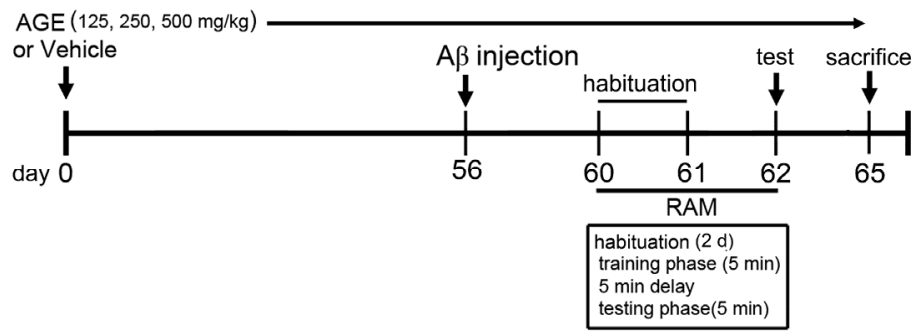

Figure 1. Schematic diagram of drug treatment and behavioural tests. Rats were injected with A $\beta$ (1-42) into both sides of the lateral ventricle after 56 days of drug treatments. (RAM: radial arm maze test, A $\beta$ : amyloid- $\beta(1-42))$.

\section{3. $A \beta(1-42)$ Treatment}

A $\beta$ (1-42) peptide (Alexis Biochemicals, San Diego, CA, USA) was dissolved in glacial acetic acid at a concentration of $1 \mathrm{mg} / \mathrm{mL}$ and incubated at $37{ }^{\circ} \mathrm{C}$ for $24 \mathrm{~h}$ to cause peptide aggregation. The rats were anesthetized with thiopental sodium $(35 \mathrm{mg} / \mathrm{kg} \mathrm{BW}$, intraperitoneal) and then injected with $1 \mu \mathrm{L}$ of aggregated $\mathrm{A} \beta(1-42)$ peptide bilaterally into the lateral ventricle at a rate of $0.2 \mu \mathrm{L} / \mathrm{min}$, with stereotaxic coordinates of anterior-posterior (AP)- $0.8 \mathrm{~mm}$ from the bregma, lateral (L) $\pm 1.5 \mathrm{~mm}$ from the midline, and superior-inferior (SI)-3.8 mm from the dura [28]. After injection, the needle was slowly removed. The rats were kept on a warm pad $\left(32-33^{\circ} \mathrm{C}\right)$ and returned to their cages. 


\subsection{Radial Arm Maze Test (RAM)}

Working and reference memory were measured using an eight-arm radial maze $(11 \mathrm{~cm} \times 50 \mathrm{~cm})$ extending radially from a central area $(30 \mathrm{~cm}$ wide octagon). The maze was placed $50 \mathrm{~cm}$ above the floor and surrounded by various extra-maze visual cues located in the same positions throughout the study. A food cup was located at the distal end of each arm. Before the testing began, the rats were habituated to the maze environment for two consecutive days, after which subsequent performance tests were conducted. These trials consisted of a training phase and a test phase, separated by a delay. In the training phase, the four arms (arms 1, 4, 6, and 7) were randomly blocked, and the four remaining arms (arms 2, 3, 5, and 8) were baited (Figure 2A). Each rat was given $5 \mathrm{~min}$. to enter the four open arms or retrieve the bait, after which it was returned to its home cage for the delay period. After a $5 \mathrm{~min}$. delay, each rat was placed back into the maze for the test phase. During the test phase, all eight arms were opened. However, the bait was only in the arms that had previously been blocked (Figure 2B). The number of arm entries was recorded along with two types of errors: working memory errors (re-entries into an arm containing food or an arm not baited), and reference memory errors (entering an arm that does not contain the bait). The maze was cleaned with a $20 \%$ ethanol solution and dried with a cloth before the next animal was tested [30].

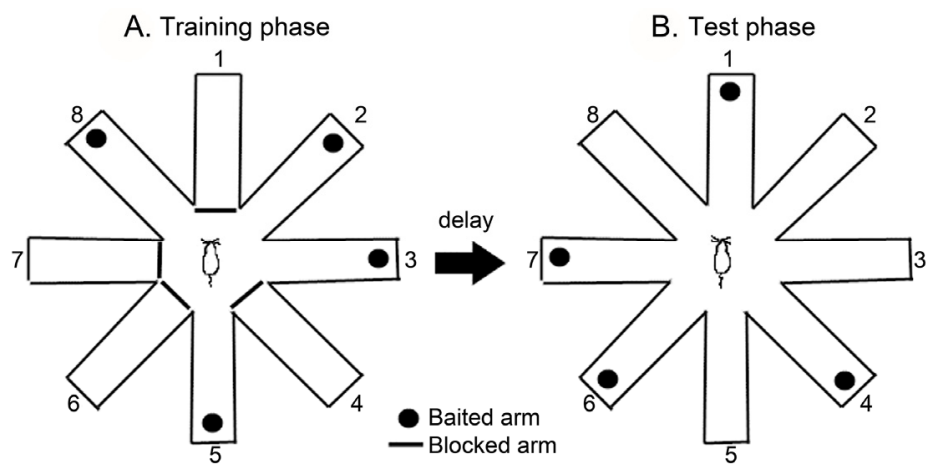

Figure 2. The schematic diagram of the eight-arm radial maze. The animals were tested in the RAM with a 5 min delay.

\subsection{Tissue Preparation}

After euthanasia, the whole brain of each rat was quickly removed, put on ice and cut at the midline dividing the brain into left and right hemispheres. The left hemisphere was cryopreserved in sucrose solution $(30 \%)$ and fixed in ice cold $4 \%$ paraformaldehyde solution for immunohistochemical investigation of ChAT using a free-floating technique. The hippocampus was taken from the right hemisphere and homogenized immediately $(10 \% w / v$ homogenate $)$ in an ice-cold medium containing $20 \mathrm{mM}$ Tris- $\mathrm{HCl}(\mathrm{pH} 7.4)$ and $320 \mathrm{mM}$ sucrose. The homogenate was centrifuged at $15,000 \times g$ at $4{ }^{\circ} \mathrm{C}$ for $10 \mathrm{~min}$. The supernatant was used for Western blot analysis of GAD, VGLUT1, and VGLUT2.

\subsection{Immunohistochemistry}

Immunohistochemical staining for the ChAT enzyme was performed on serial and coronal sections of the entire brain using the free-floating technique. The $35 \mu \mathrm{m}$-thick sections were cut using a sliding microtome (Thermo, Walldorf, Germany) and put in cold $0.01 \mathrm{M}$ phosphate-buffered saline (PBS), $\mathrm{pH}$ 7.4. The first series of immunohistochemistry analyses of the ChAT enzyme was performed on free-floating sections at $4{ }^{\circ} \mathrm{C}$. Sections were then incubated in blocking serum $(1 \%$ bovine serum albumin in PBS) for $1 \mathrm{~h}$ and further incubated overnight with a polyclonal antibody for ChAT (1:100, Merck Millipore, Darmstadt, Hesse, Germany) in blocking serum at $4{ }^{\circ} \mathrm{C}$. Then, the sections were incubated with peroxidase conjugated secondary antibody (1:1000, Invitrogen, Carlsbad, CA, USA) for $2 \mathrm{~h}$. After being washed in PBS, the sections were treated with $0.001 \%$ of 
diaminobenzidine tetrahydrochloride dihydrate (Sigma, St. Louis, MO, USA) in PBS containing $0.003 \% \mathrm{H}_{2} \mathrm{O}_{2}$ (Merck Millipore, Darmstadt, Hesse, Germany). The sections were then mounted on gelatin-coated glass slides, allowed to dry overnight, counterstained with cresyl violet, dehydrated and cover-slipped under DPX (Sigma, St. Louis, MO, USA). All slides were examined under a light microscope (Nikon Microscope ECLIPSE E200 MVR, Nikon Corp, Tokyo, Japan) at $40 \times$ objective. A Prosilica GT digital camera (Dynatech Inst, Bangkok, Thailand) connected to a computer was mounted on top of the microscope. Every forth section throughout the entire rostrocaudal extent of the hippocampus of each brain was selected for a blind count of ChAT-immunoreactive cells in the hippocampus. The raw data were multiplied by four to achieve an estimate of the total number of ChAT-immunoreactive cells in each hippocampus sample. The number of ChAT-immunoreactive cells was analysed using the method modification described by Huang and Herbert (2006) [31].

\subsection{Western Blot Analysis}

Hippocampal tissue was prepared for Western blotting as has been previously described [32]. The protein concentrations (10 $\mu \mathrm{g}$ per lane, VGLUT1; $50 \mu \mathrm{g}$ per lane, VGLUT2; $30 \mu \mathrm{g}$ per lane, GAD) were separated by $10 \%$ SDS-PAGE (Bio-Rad Laboratories $\mathrm{GmbH}$, Munich, Germany), transferred to a nitrocellulose membrane and blocked with 5\% skim milk (Sigma, St. Louis, MO, USA) in 25 mM Tris-buffer saline containing $0.1 \%$ Tween 20 (TBS-T) at room temperature for $1 \mathrm{~h}$. The membranes were then separately incubated with primary antibodies, including anti-VGLUT1 antibody (1:100, Abcam, Milton, Cambridge, UK), anti-VGLUT2 antibody (1:1000, Abcam, Milton, Cambridge, UK), anti-GAD 65 and 67 antibodies (1:1000, Merck Millipore, Darmstadt, Hesse, Germany), and GADPH as a reference protein (1:20,000, Abcam, Milton, Cambridge, UK), in TBS-T at $4{ }^{\circ} \mathrm{C}$ for $24 \mathrm{~h}$. After extensive washing with TBS-T, the membranes were incubated with peroxidase-conjugated secondary antibody (1:1000, Merck Millipore, Darmstadt, Hesse, Germany) at room temperature for $2 \mathrm{~h}$. Signals were visualized using a chemiluminescence substrate (Thermo Scientific, Waltham, MA, USA) and exposed onto film. The optical density of the bands was calculated after background subtraction using Image J analysis software (Windows version, National Institutes of Health, Bethesda, MD, USA).

\subsection{Statistical Analysis}

All statistical parameters were calculated using GraphPad Prism V 5.0 (GraphPad Software, LaJolla, CA, USA). The data are expressed as means \pm standard error of mean (S.E.M.) of variance (ANOVA). This was followed by a post hoc Bonferoni test. A probability level of less than 0.05 was accepted as significant.

\section{Results}

\subsection{Effect of AGE on Working and Reference Memory in Radial Arm Maze Test}

As shown in Figure 3, A $\beta$-treated rats showed significant deficits in terms of the mean number of errors in working and reference memory ( $p<0.01$ and 0.05 , respectively). When compared to the vehicle plus $A \beta$ groups, the mean number of errors in groups that received AGE at any dose indicated that AGE significantly prevented working memory loss (One way ANOVA test, $F_{4,35}=17.23, p<0.05$ and $p<0.01$ ). There were also decreases in the mean number of errors related to reference memory, but this difference was not statistically significant (one-way ANOVA test, $F_{4,35}=2.93, p>0.05$ ). These results indicate that exposure to AGE could improve working memory as demonstrated through the use of the RAM. 


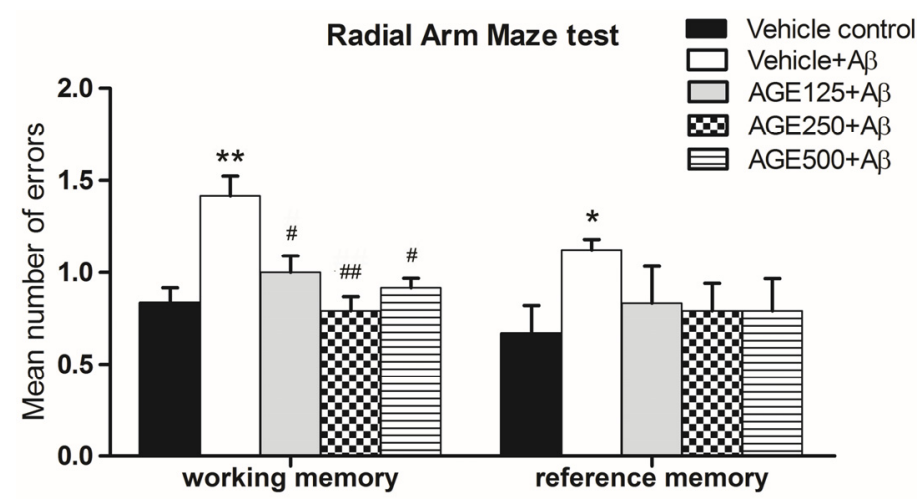

Figure 3. Number of working memory errors and reference memory errors made while looking for the baited arm in the RAM on day 6 after A $\beta$ injection. Data are presented as mean \pm S.E.M. $(n=8),{ }^{*}, * *$ significant differences from the vehicle control group at $p<0.05$ and 0.01 , respectively; $\#, \#$, significant differences from the vehicle $+\mathrm{A} \beta$ group at $p<0.05$ and 0.01 , respectively.

\subsection{Effect of AGE on Cholinergic Neurons in the Hippocampal Region}

Immunohistochemical study performed with the ChAT antibody showed long positive fibres of pyramidal-like cells throughout the hippocampal formation in all groups (Figure 4). Choline acetyltransferase-immunoreactive cells were relatively large and were observed in all layers of the hippocampus. When compared to the vehicle control group, the density of ChAT-immunoreactive cells in all regions of the hippocampus of the vehicle plus $\mathrm{A} \beta$ group was significantly lower $(p<0.001)$. Although all doses of AGE exhibited a neuroprotective effect against $A \beta$-induction neurotoxicity, only AGE at a dose of $250 \mathrm{mg} / \mathrm{kg}$ BW significantly restored the density of cholinergic neurons in the hippocampus $(p<0.01)$ (Figure $4 \mathrm{G}$ ).

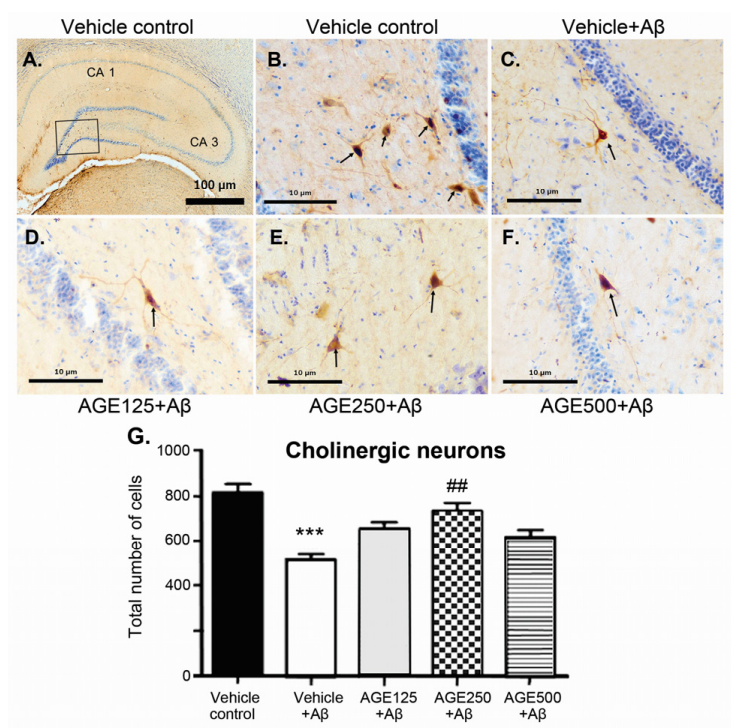

Figure 4. The neuroprotective effect of AGE (aged garlic extract) on cholinergic neurons in the hippocampal region of $\mathrm{A} \beta$-induced rats. (A-F) represent the photomicrographs of brain section showing the distribution of cholinergic neurons by double staining of Nissl stain with cresyl violet and immunohistochemistry stained with polyclonal ChAT (choline acetyltransferase) antibodies in the vehicle control group (A and B), vehicle $+\mathrm{A} \beta$ (C), AGE125 + A $\beta$ (D), AGE250 + A $\beta$ (E) and AGE $500+A \beta(F) .(G)$ represents the number of ChAT neurons. The cholinergic neurons are indicated with arrows. Data are presented as mean \pm S.E.M. $(n=8),{ }^{* * *}=$ significant differences from the vehicle control group at $p<0.001$ and ${ }^{\# \#}=$ significant differences from the vehicle $+\mathrm{A} \beta$ group at $p<0.01$. 


\subsection{Effect of AGE on VGLUT1, VGLUT2, and GAD 65 and 67 in the Hippocampal Region}

Western blot analysis showed the differentiated effect of AGE on levels of VGLUT1, VGLUT2, and GAD 65 and 67 in the hippocampal region of the rat brain. A $\beta$ significantly reduced the levels of VGLUT1 and GAD 65 and $67(p<0.001)$ but did not affect VGLUT2 levels in the hippocampus (Figure 5). At a dose of $250 \mathrm{mg} / \mathrm{kg}$ BW AGE significantly increased the amount of VGLUT1 $(p<0.01)$ compared to vehicle plus A $\beta$. In contrast, AGE did not affect VGLUT2 levels in the hippocampal region at any dose. Treatment with medium and high doses of AGE markedly increased the amount of GAD 65 and $67(p<0.001)$ in the hippocampal region of the rat brain in a dose-dependent manner.

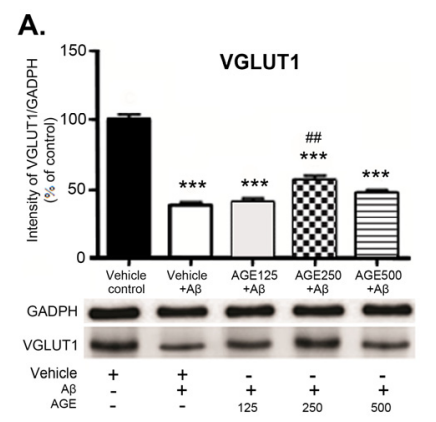

B.
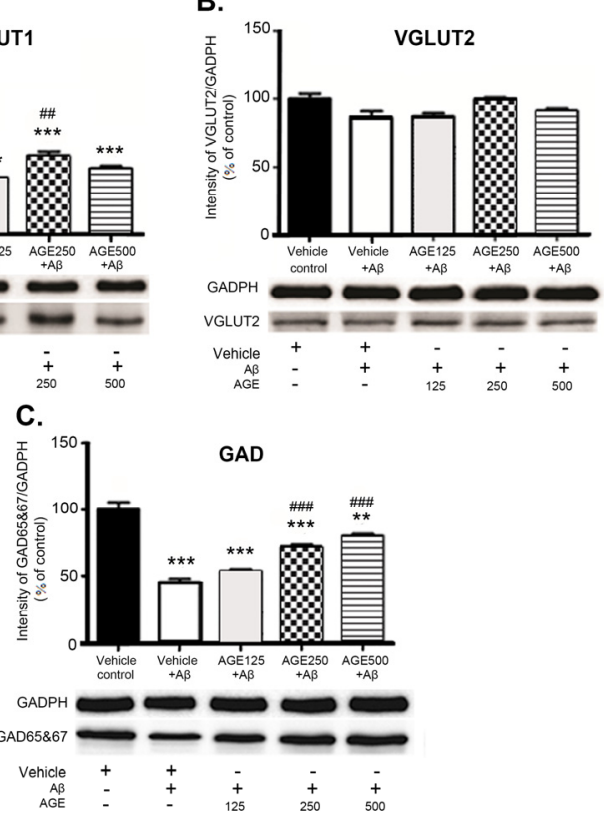

Figure 5. Effects of AGE on amounts of VGLUT1 (A), VGLUT2 (B) and GAD 65 and 67 (C) in the rat hippocampus. Data are presented as mean \pm S.E.M $(n=8),{ }^{* *},{ }^{* * *}=$ significant differences from the

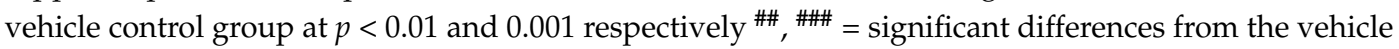
$+\mathrm{A} \beta$ group at $p<0.01$ and 0.001 , respectively. VGLUT1 and VGLUT2, vesicular glutamate transporter 1 and 2 proteins; GAD, glutamate decarboxylase.

\section{Discussion}

Degenerating neurons and synapses in the Alzheimer's brain are located predominantly within susceptible regions including the hippocampus and cerebral cortex [33]. Biochemical investigations of brain tissue indicate that various neurotransmitters and modulators, including ACh, VGLUT and GABA, are differentially affected in various regions of Alzheimer's brain [25,34,35]. The major component of senile plaques in the Alzheimer's brain is the A $\beta$ peptide. Neurons, glial cells, or synaptic markers can also be altered functionally and structurally by excessive $A \beta$ levels [36,37]. The present study found that administration of $A \beta(1-42)$ into the lateral ventricle caused significant decreases the number of ChAT-immunoreactive cells in the hippocampus (Figure 4). This is consistent with previous reports of $A \beta$ oligomers inducing a major reduction in ChAT activity [38] and the lack of ChAT viability by attaching specifically to excitatory synapses, leading to cholinergic synapse dysfunction and cognitive impairment [39]. However, the persistence of cholinergic neurons in the hippocampus has been controversial and, according to some investigators, failed to be detected with immunohistochemical techniques [40]. Some studies reported the presence of ChAT-immunoreactive interneurons in the hippocampus [41-44]. Previous studies have reported that there are low numbers of ChAT-immunoreactive cells in the hippocampus. These cells are the interneurons, not the principal 
cells $[44,45]$. Although there is no clear role of these interneurons, Hefft et al. have shown that nicotinic acethylcholine receptors can be synaptically activated in rat hippocampal organotypic cultures [46]. However, the support on these findings still need further investigation. We also found that $A \beta(1-42)$ caused predominant losses of glutamatergic and GABAergic markers in the hippocampus, as indicated by significant decreases in VGLUT1 and GAD densities (Figure 5). However, VGLUT2 density in the hippocampus of $A \beta$ groups was not significantly different to those in the vehicle control. These findings are consistent with a previous report of decreases in the density of VGLUT1 and GAD $[25,47]$, but not VGLUT2 in the hippocampus of A $\beta$-injected mice. Since VGLUT1 was found in the hippocampus more often than VGLUT2 [25], VGLUT2 is generally considered as a marker of glutamatergic neurons of thalamic origin. This may be the reason that $A \beta$ toxicity does not result in changes in VGLUT2 in the hippocampus [48]. Moreover, $\mathrm{A} \beta$ (1-42), $\mathrm{A} \beta$ (31-35), and A $\beta$ (34-39) toxicity was shown to decrease the number of GABAergic and glutaminergic neurons, suggesting that the degeneration of both neuronal groups is an indicator of early pathological changes in the brain [35]. Our results demonstrate that AGE exhibited a neuroprotective effect. Pretreatment of AGE at $250 \mathrm{mg} / \mathrm{kg}$ BW can prevent the decreases in the density of VGLUT1 and GAD in the hippocampus and protect from the loss of cholinergic neurons induced by A $\beta$ (1-42). In terms of consumption, AGE at a dose of $250 \mathrm{mg} / \mathrm{kg}$ used in this study is equivalent to $6.5 \mathrm{~g}$ or 2-3 cloves of fresh garlic. These findings are in agreement with those of previous reports that AGE and SAC protected ChAT activity from reactive oxygen species (ROS) and mediated $A \beta$-induced damage in differentiated human cells. AGE treatment also reverses ROS-mediated declines in cholinergic function of neuronal cells by increasing levels of neuronal ChAT activity [26]. Treatment with AGE has been shown to restore the hypothalamic ChAT activity in thymectomized mice when compared to sham-operated controls [49]. However, the effects of AGE on glutamatergic and GABAergic systems was studied. These findings suggest that AGE can reverse the loss of cholinergic, glutamatergic, and GABAergic markers in cases of $A \beta$ toxicity. This may result from AGE modifying cells' defensive mechanisms. Furthermore, the chemical structure of organosulfur compounds present in the AGE, including SAC (major ingredient $30.96 \mathrm{mg} / \mathrm{g}$ ), have allyl chains that could bind to the hydrophobic regions of $A \beta$ and, thus, inhibit A $\beta$ fibril formation [50]. Since adenosine and its degradative enzyme, adenosine deaminase, were reported to be modulated by garlic extract in the rat hippocampus, it should be noted that this adenosine may also play certain roles in the neuroprotective effect of AGE [51]. In addition, previous studies have reported that aqueous extract of garlic promoted adenosine signalling in the adenosine system of rat cardiac injury [52]. The dysfunction or damage of presynaptic cholinergic, glutamatergic, and GABAergic markers in the hippocampus was related to memory impairment in the $A \beta$-induced rats $[53,54]$. We found that administration of $A \beta(1-42)$ into the lateral ventricle caused deficits in working and reference spatial memory, as evaluated by a RAM task. This is consistent with previous reports of $A \beta$-injected rats showing significant deficits in spatial cognition in the Morris water maze (MWM) [36], Y-maze [20], and a RAM task [55,56]. A $\beta$ deposition might differentially affect excitatory and inhibitory synapses and cells, producing complex imbalances in circuit and network activity [57]. The present study demonstrated that all doses of AGE can protect against neurotoxicity caused by $A \beta$, as demonstrated by improvements in working memory. Although AGE did not significantly enhance reference memory, it did have a tendency to restore it. It has been suggested that AGE could improve working and reference memory as demonstrated through the use of RAM tasks. Moreover, AGE at doses of 250 and $500 \mathrm{mg} / \mathrm{kg}$ were able to protect against neurotoxicity caused by $\mathrm{A} \beta$ induction, as demonstrated by improvements in short-term spatial memory by MWM [58]. This is consistent with previous study of AGE treated rats showing ameliorate deficits in both short term and long term aspects of spatial memory as evaluated by MWM performance in senescence-accelerated mice [29]. AGE has also been shown to improve recognition memory, as evaluated by novel objective recognition in A $\beta$-induced rats [28]. Since working or short-term memory is a critical cognitive system used when remembering objects or places during goal-directed behaviour. Reference or long-term memory is required for temporally stable memories of those objects or places [59]. Furthermore, 
preliminary studies on pre-treatment of AGE at doses of 125, 250, and $500 \mathrm{mg} / \mathrm{kg}$ BW for 30 days. The results of RAM showed that all AGE-treated groups tended to remember the spatial location of short- term and long-term spatial memory better than the normal control. Moreover, all AGE doses significantly increased short-term and long-term memory $(p<0.05)$ by using MWM (data not shown). Therefore, it is possible that AGE may be effective in promoting the spatial memory in rats.

\section{Conclusions}

Our results demonstrated that AGE improved the working and reference spatial memory, by using RAM tests and is associated with increases in markers of VGLU1 and GAD proteins and ChAT-immunoreactive cells in the hippocampus of rat with $A \beta$-induced neurotoxicity. Therefore, we conclude that there may be health benefits associated with the consumption of aged garlic.

Acknowledgments: This study was supported by the Higher Education Research Promotion and National Research, the University Project of Thailand, the Office of the Higher Education Commission, through the Food and Functional Food Research Cluster of Khon Kaen University and the Centre for Research and Development of Herbal Health Products (CRD-HHP) under grant M 54152, and by the Khon Kaen University Faculty of Medicine (Khon Kaen Thailand), under grant IN 58124. We would like to thank Dylan Southard, Human Sciences) for his assistance with the English-language presentation of this manuscript.

Author Contributions: W.P. conceived and designed the experiments; P.T., W.P., K.S., J.U.W., and W.C. performed the experiments and analysed the data; B.S., W.P., W.C., and J.U.W. contributed to the reagents and materials; W.P., B.S., and K.S. guided research; P.T., W.P., and B.S. drafted the manuscript; and W.P. and B.S. revised the manuscript content. All authors read and approved the final manuscript.

Conflicts of Interest: The authors declare no conflict of interest.

\section{Abbreviations}

The following abbreviations are used in this manuscript:

\begin{tabular}{|c|c|}
\hline $\mathrm{ACh}$ & Acetylcholine \\
\hline $\mathrm{AD}$ & Alzheimer's disease \\
\hline AGE & Aged garlic extract \\
\hline ANOVA & Analysis of variance \\
\hline AP & Anterior-posterior \\
\hline$A \beta$ & $\beta$-amyloid \\
\hline BW & Body weight \\
\hline $\mathrm{Ca}^{2+}$ & Calcium \\
\hline ChAT & Choline acetyltransferase \\
\hline CRD-HHP & Center for Research and Development of Herbal Health Products \\
\hline DPX & Depex mounting medium \\
\hline GABA & Gamma-aminobutyric acid \\
\hline GAD & Glutamate decarboxylase \\
\hline GAPDH & Glyceraldehyde 3 phosphate dehydrogenase \\
\hline $\mathrm{H}_{2} \mathrm{O}_{2}$ & Hydrogen peroxide \\
\hline $\mathrm{HCL}$ & Hydrochloric \\
\hline HPLC & High Performance Liquid Chromatography \\
\hline MWM & Morri water maze \\
\hline PBS & Phosphate buffer saline \\
\hline $\mathrm{pH}$ & Potential of Hydrogen ion \\
\hline RAM & Radial arm maze \\
\hline ROS & Reactive oxygen species \\
\hline S.E.M. & Standard error of mean \\
\hline SAC & S-allyl cysteine \\
\hline SDS-PAGE & Sodium dodecyl sulfate polyacrylamide gel electrophoresis \\
\hline SI & Superior-inferior \\
\hline TBS-T & Tris-buffered saline containing $0.1 \%$ tween 20 \\
\hline VGLUT1 & Vesicular glutamate transporter1 \\
\hline VGLUT2 & Vesicular glutamate transporter2 \\
\hline
\end{tabular}




\section{References}

1. Khakpai, F.; Nasehi, M.; Haeri-Rohani, A.; Eidi, A.; Zarrindast, M.R. Septo-hippocampo-septal loop and memory formation. Basic Clin. Neurosci. 2013, 4, 5-23. [PubMed]

2. Centonze, D.; Picconi, B.; Gubellini, P.; Bernardi, G.; Calabresi, P. Dopaminergic control of synaptic plasticity in the dorsal striatum. Eur. J. Neurosci. 2001, 13, 1071-1077. [CrossRef] [PubMed]

3. Francis, P.T.; Palmer, A.M.; Snape, M.; Wilcock, G.K. The cholinergic hypothesis of Alzheimer's disease: A review of progress. J. Neurol. Neurosurg. Psychiatry 1999, 66, 137-147. [CrossRef] [PubMed]

4. Murtha, S.J.; Pappas, B.A. Neurochemical histopathological and mnemonic effects of combined lesions of the medial septal and serotonin afferents to the hippocampus. Brain Res. 1994, 651, 16-26. [CrossRef]

5. Huerta, P.T.; Lisman, J.E. Low-frequency stimulation at the troughs of theta-oscillation induces long-term depression of previously potentiated ca1 synapses. J. Neurophysiol. 1996, 75, 877-884. [PubMed]

6. Fremeau, R.T., Jr.; Troyer, M.D.; Pahner, I.; Nygaard, G.O.; Tran, C.H.; Reimer, R.J.; Bellocchio, E.E.; Fortin, D.; Storm-Mathisen, J.; Edwards, R.H. The expression of vesicular glutamate transporters defines two classes of excitatory synapse. Neuron 2001, 31, 247-260. [CrossRef]

7. Nakamura, K.; Hioki, H.; Fujiyama, F.; Kaneko, T. Postnatal changes of vesicular glutamate transporter (VGLUT)1 and VGLUT2 immunoreactivities and their colocalization in the mouse forebrain. J. Comp. Neurol. 2005, 492, 263-288. [CrossRef] [PubMed]

8. Zhou, J.; Nannapaneni, N.; Shore, S. Vessicular glutamate transporters 1 and 2 are differentially associated with auditory nerve and spinal trigeminal inputs to the cochlear nucleus. J. Comp. Neurol. 2007, 500, 777-787. [CrossRef] [PubMed]

9. Todd, A.J.; Hughes, D.I.; Polgar, E.; Nagy, G.G.; Mackie, M.; Ottersen, O.P.; Maxwell, D.J. The expression of vesicular glutamate transporters VGLUT1 and VGLUT2 in neurochemically defined axonal populations in the rat spinal cord with emphasis on the dorsal horn. Eur. J. Neurosci. 2003, 17, 13-27. [CrossRef]

10. Mann, E.O.; Paulsen, O. Role of gabaergic inhibition in hippocampal network oscillations. Trends Neurosci. 2007, 30, 343-349. [CrossRef] [PubMed]

11. Sheikh, S.N.; Martin, S.B.; Martin, D.L. Regional distribution and relative amounts of glutamate decarboxylase isoforms in rat and mouse brain. Neurochem. Int. 1999, 35, 73-80. [CrossRef]

12. Kirwan, C.B.; Gilbert, P.E.; Kesner, R.P. The role of the hippocampus in the retrieval of a spatial location. Neurobiol. Learn. Mem. 2005, 83, 65-71. [CrossRef] [PubMed]

13. Figueredo, L.Z.P.; Moreira, K.M.; Ferreira, T.L.; Fornari, R.V.; Oliveira, M.G.M. Interaction between glutamatergic-NMDA and cholinergic-muscarinic systems in classical fear conditioning. Brain Res. Bull. 2008, 77, 71-76. [CrossRef] [PubMed]

14. Lujan, R.; Shigemoto, R.; Lopez-Bendito, G. Glutamate and GABA receptor signalling in the developing brain. Neuroscience 2005, 130, 567-580. [CrossRef] [PubMed]

15. Cui, B.; Wu, M.Q.; She, X.J. Effects of chronic noise exposure on spatial learning and memory of rats in relation to neurotransmitters and NMDAR2B alteration in the hippocampus. J. Occup. Health 2009, 51, 152-158. [CrossRef] [PubMed]

16. Francis, P.T. Glutamatergic systems in Alzheimer's disease. Int. J. Geriatr. Psychiatry 2003, 18, S15-S21. [CrossRef] [PubMed]

17. Lowe, S.L.; Francis, P.T.; Procter, A.W.; Palmer, A.M.; Davison, A.N.; Bowen, D.M. Gamma-aminobutyric acid concentration in brain tissue at two stages of Alzheimer's disease. Brain 1988, 111, 785-799. [CrossRef] [PubMed]

18. Solas, M.; Puerta, E.; Ramirez, M.J. Treatment options in alzheimer s disease: The GABA story. Curr. Pharm. Des. 2015, 21, 4960-4971. [CrossRef] [PubMed]

19. Bagheri, M.; Joghataei, M.T.; Mohseni, S.; Roghani, M. Genistein ameliorates learning and memory deficits in amyloid beta(1-40) rat model of Alzheimer's disease. Neurobiol. Learn. Mem. 2011, 95, 270-276. [CrossRef] [PubMed]

20. Dall'Igna, O.P.; Fett, P.; Gomes, M.W.; Souza, D.O.; Cunha, R.A.; Lara, D.R. Caffeine and adenosine a(2a) receptor antagonists prevent beta-amyloid (25-35)-induced cognitive deficits in mice. Exp. Neurol. 2007, 203, 241-245. [CrossRef] [PubMed] 
21. Chen, G.; Chen, K.S.; Knox, J.; Inglis, J.; Bernard, A.; Martin, S.J.; Justice, A.; McConlogue, L.; Games, D.; Freedman, S.B.; et al. A learning deficit related to age and beta-amyloid plaques in a mouse model of Alzheimer's disease. Nature 2000, 408, 975-979. [CrossRef] [PubMed]

22. Shen, Y.; Lue, L.; Yang, L.; Roher, A.; Kuo, Y.; Strohmeyer, R.; Goux, W.J.; Lee, V.; Johnson, G.V.; Webster, S.D.; et al. Complement activation by neurofibrillary tangles in Alzheimer's disease. Neurosci. Lett. 2001, 305, 165-168. [CrossRef]

23. Shin, K.; Guo, H.; Cha, Y.; Ban, Y.H.; Seo, D.W.; Choi, Y.; Kim, T.S.; Lee, S.P.; Kim, J.C.; Choi, E.K.; et al. Cereboost ${ }^{\mathrm{TM}}$, an american ginseng extract, improves cognitive function via up-regulation of choline acetyltransferase expression and neuroprotection. Regul. Toxicol. Pharm. 2016, 78, 53-58. [CrossRef] [PubMed]

24. Lim, G.P.; Chu, T.; Yang, F.S.; Beech, W.; Frautschy, S.A.; Cole, G.M. The curry spice curcumin reduces oxidative damage and amyloid pathology in an Alzheimer transgenic mouse. J. Neurosci. 2001, 21, 8370-8377. [PubMed]

25. Canas, P.M.; Simoes, A.P.; Rodrigues, R.J.; Cunha, R.A. Predominant loss of glutamatergic terminal markers in a beta-amyloid peptide model of Alzheimer's disease. Neuropharmacology 2014, 76, 51-56. [CrossRef] [PubMed]

26. Ray, B.; Chauhan, N.B.; Lahiri, D.K. Oxidative insults to neurons and synapse are prevented by aged garlic extract and S-allyl-L-cysteine treatment in the neuronal culture and APP-Tg mouse model. J. Neurochem. 2011, 117, 388-402. [CrossRef] [PubMed]

27. Moriguchi, T.; Saito, H.; Nishiyama, N. Aged garlic extract prolongs longevity and improves spatial memory deficit in senescence-accelerated mouse. Biol. Pharm. Bull. 1996, 19, 305-307. [CrossRef] [PubMed]

28. Nillert, N.; Pannangrong, W.; Welbat, J.U.; Chaijaroonkhanarak, W.; Sripanidkulchai, K.; Sripanidkulchai, B. Neuroprotective effects of aged garlic extract on cognitive dysfunction and neuroinflammation induced by beta-amyloid in rats. Nutrients 2017, 9, 24. [CrossRef] [PubMed]

29. Moriguchi, T.; Saito, H.; Nishiyama, N. Anti-ageing effect of aged garlic extract in the inbred brain atrophy mouse model. Clin. Exp. Pharmacol. Physiol. 1997, 24, 235-242. [CrossRef] [PubMed]

30. Espina-Marchant, P.; Pinto-Hamuy, T.; Bustamante, D.; Morales, P.; Robles, L.; Herrera-Marschitz, M. Spatial cognition and memory: A reversible lesion with lidocaine into the anteromedial/posterior parietal cortex (AM/PPC) affects differently working and long-term memory on two foraging tasks. Biol. Res. 2006, 39, 601-609. [CrossRef] [PubMed]

31. Huang, G.J.; Herbert, J. Stimulation of neurogenesis in the hippocampus of the adult rat by fluoxetine requires rhythmic change in corticosterone. Biol. Psychiatry 2006, 59, 619-624. [CrossRef] [PubMed]

32. Mustafa, S.; Walker, A.; Bennett, G.; Wigmore, P.M. 5-fluorouracil chemotherapy affects spatial working memory and newborn neurons in the adult rat hippocampus. Eur. J. Neurosci. 2008, 28, 323-330. [CrossRef] [PubMed]

33. DeKosky, S.T.; Scheff, S.W.; Styren, S.D. Structural correlates of cognition in dementia: Quantification and assessment of synapse change. Neurodegeneration 1996, 5, 417-421. [CrossRef] [PubMed]

34. Auld, D.S.; Kornecook, T.J.; Bastianetto, S.; Quirion, R. Alzheimer's disease and the basal forebrain cholinergic system: Relations to beta-amyloid peptides, cognition, and treatment strategies. Prog. Neurobiol. 2002, 68, 209-245. [CrossRef]

35. Marczynski, T.J. Gabaergic deafferentation hypothesis of brain aging and Alzheimer's disease revisited. Brain Res. Bull. 1998, 45, 341-379. [CrossRef]

36. Medeiros, R.; Prediger, R.D.S.; Passos, G.F.; Pandolfo, P.; Duarte, F.S.; Franco, J.L.; Dafre, A.L.; Di Giunta, G.; Figueiredo, C.P.; Takahashi, R.N.; et al. Connecting TNF-alpha signaling pathways to iNOS expression in a mouse model of Alzheimer's disease: Relevance for the behavioral and synaptic deficits induced by amyloid beta protein. J. Neurosci. 2007, 27, 5394-5404. [CrossRef] [PubMed]

37. Canas, P.M.; Porciuncula, L.O.; Cunha, G.M.A.; Silva, C.G.; Machado, N.J.; Oliveira, J.M.A.; Oliveira, C.R.; Cunha, R.A. Adenosine A2A receptor blockade prevents synaptotoxicity and memory dysfunction caused by beta-amyloid peptides via p38 mitogen-activated protein kinase pathway. J. Neurosci. 2009, 29, 14741-14751. [CrossRef] [PubMed]

38. Nitta, A.; Fukuta, T.; Hasegawa, T.; Nabeshima, T. Continuous infusion of beta-amyloid protein into the rat cerebral ventricle induces learning impairment and neuronal and morphological degeneration. Jpn. J. Pharmacol. 1997, 73, 51-57. [CrossRef] [PubMed] 
39. Nunes-Tavares, N.; Santos, L.E.; Stutz, B.; Brito-Moreira, J.; Klein, W.L.; Ferreira, S.T.; de Mello, F.G. Inhibition of choline acetyltransferase as a mechanism for cholinergic dysfunction induced by amyloid-beta peptide oligomers. J. Biol. Chem. 2012, 287, 19377-19385. [CrossRef] [PubMed]

40. Blusztajn, J.K.; Rinnofner, J. Intrinsic cholinergic neurons in the hippocampus: Fact or artifact? Front. Synaptic Neurosci. 2016, 8, 6. [CrossRef] [PubMed]

41. Frotscher, M.; Schlander, M.; Léránth, C. Cholinergic neurons in the hippocampus. A combined light- and electron-microscopic immunocytochemical study in the rat. Cell Tissue Res. 1986, 246, 293-301. [CrossRef] [PubMed]

42. Blaker, S.N.; Armstrong, D.M.; Gage, F.H. Cholinergic neurons within the rat hippocampus: Response to fimbria-fornix transection. J. Comp. Neurol. 1988, 272, 127-138. [CrossRef] [PubMed]

43. Matthews, D.A.; Salvaterra, P.M.; Crawford, G.D.; Houser, C.R.; Vaughn, J.E. An immunocytochemical study of choline acetyltransferase-containing neurons and axon terminals in normal and partially deafferented hippocampal formation. Brain Res. 1987, 402, 30-43. [CrossRef]

44. Yi, F.; Catudio-Garrett, E.; Gabriel, R.; Wilhelm, M.; Erdelyi, F.; Szabo, G.; Deisseroth, K.; Lawrence, J. Hippocampal "cholinergic interneurons" visualized with the choline acetyltransferase promoter: Anatomical distribution, intrinsic membrane properties, neurochemical characteristics, and capacity for cholinergic modulation. Front. Synaptic Neurosci. 2015, 7, 4. [CrossRef] [PubMed]

45. Frotscher, M.; Vida, I.; Bender, R. Evidence for the existence of non-gabaergic, cholinergic interneurons in the rodent hippocampus. Neuroscience 2000, 96, 27-31. [CrossRef]

46. Hefft, S.; Hulo, S.; Bertrand, D.; Muller, D. Synaptic transmission at nicotinic acetylcholine receptors in rat hippocampal organotypic cultures and slices. J. Physiol. 1999, 515, 769-776. [CrossRef] [PubMed]

47. Bell, K.F.S.; de Kort, G.J.L.; Steggerda, S.; Shigemoto, R.; Ribeiro-da-Silva, A.; Cuello, A.C. Structural involvement of the glutamatergic presynaptic boutons in a transgenic mouse model expressing early onset amyloid pathology. Neurosci. Lett. 2003, 353, 143-147. [CrossRef] [PubMed]

48. Fremeau, R.T.; Kam, K.; Qureshi, T.; Johnson, J.; Copenhagen, D.R.; Storm-Mathisen, J.; Chaudhry, F.A.; Nicoll, R.A.; Edwards, R.H. Vesicular glutamate transporters 1 and 2 target to functionally distinct synaptic release sites. Science 2004, 304, 1815-1819. [CrossRef] [PubMed]

49. Zhang, Y.X.; Moriguchi, T.; Saito, H.; Nishiyama, N. Functional relationship between age-related immunodeficiency and learning deterioration. Eur. J. Neurosci. 1998, 10, 3869-3875. [CrossRef] [PubMed]

50. Gupta, V.B.; Indi, S.S.; Rao, K.S. Garlic extract exhibits antiamyloidogenic activity on amyloid-beta fibrillogenesis: Relevance to Alzheimer's disease. Phytother. Res. 2009, 23, 111-115. [CrossRef] [PubMed]

51. Belle, L.P.; de Bona, K.S.; Abdalla, F.H.; Pimentel, V.C.; Pigatto, A.S.; Moretto, M.B. Comparative evaluation of adenosine deaminase activity in cerebral cortex and hippocampus of young and adult rats: Effect of garlic extract (Allium sativum L.) on their susceptibility to heavy metal exposure. Basic Clin. Pharmacol. Toxicol. 2009, 104, 408-413. [CrossRef] [PubMed]

52. Sharma, A.K.; Munajjam, A.; Vaishnav, B.; Sharma, R.; Sharma, A.; Kishore, K.; Sharma, A.; Sharma, D.; Kumari, R.; Tiwari, A.; et al. Involvement of adenosine and standardization of aqueous extract of garlic (Allium sativum Linn.) on cardioprotective and cardiodepressant properties in ischemic preconditioning and myocardial ischemia-reperfusion induced cardiac injury. J. Biomed. Res 2012, 26, 24-36. [CrossRef]

53. Masliah, E.; Terry, R.D.; DeTeresa, R.M.; Hansen, L.A. Immunohistochemical quantification of the synapse-related protein synaptophysin in Alzheimer disease. Neurosci. Lett. 1989, 103, 234-239. [CrossRef]

54. Sze, C.I.; Bi, H.; Kleinschmidt-DeMasters, B.K.; Filley, C.M.; Martin, L.J. Selective regional loss of exocytotic presynaptic vesicle proteins in Alzheimer's disease brains. J. Neurol. Sci. 2000, 175, 81-90. [CrossRef]

55. Limon, I.D.; Mendieta, L.; Diaz, A.; Chamorro, G.; Espinosa, B.; Zenteno, E.; Guevara, J. Neuroprotective effect of alpha-asarone on spatial memory and nitric oxide levels in rats injected with amyloid-beta (25-35). Neurosci. Lett. 2009, 453, 98-103. [CrossRef] [PubMed]

56. Hanna, A.; Horne, P.; Yager, D.; Eckman, C.; Eckman, E.; Janus, C. Amyloid beta and impairment in multiple memory systems in older transgenic APP TgCRND8 mice. Genes Brain Behav. 2009, 8, 676-684. [CrossRef] [PubMed]

57. Mucke, L.; Selkoe, D.J. Neurotoxicity of amyloid beta-protein: Synaptic and network dysfunction. Csh Perspect. Med. 2012, 2. [CrossRef] 
58. Wichai, T.; Pannangrong, W.; Welbat, J.U.; Chaichun, A.; Sripanidkulchai, K.; Sripanidkulchai, B. Effects of aged garlic extract on spatial memory and oxidative damage in the brain of $\beta$-amyloid induced rats. (submitted).

59. Penley, S.C.; Gaudet, C.M.; Threlkeld, S.W. Use of an eight-arm radial water maze to assess working and reference memory following neonatal brain injury. J. Vis. Exp. 2013. [CrossRef] [PubMed] 